
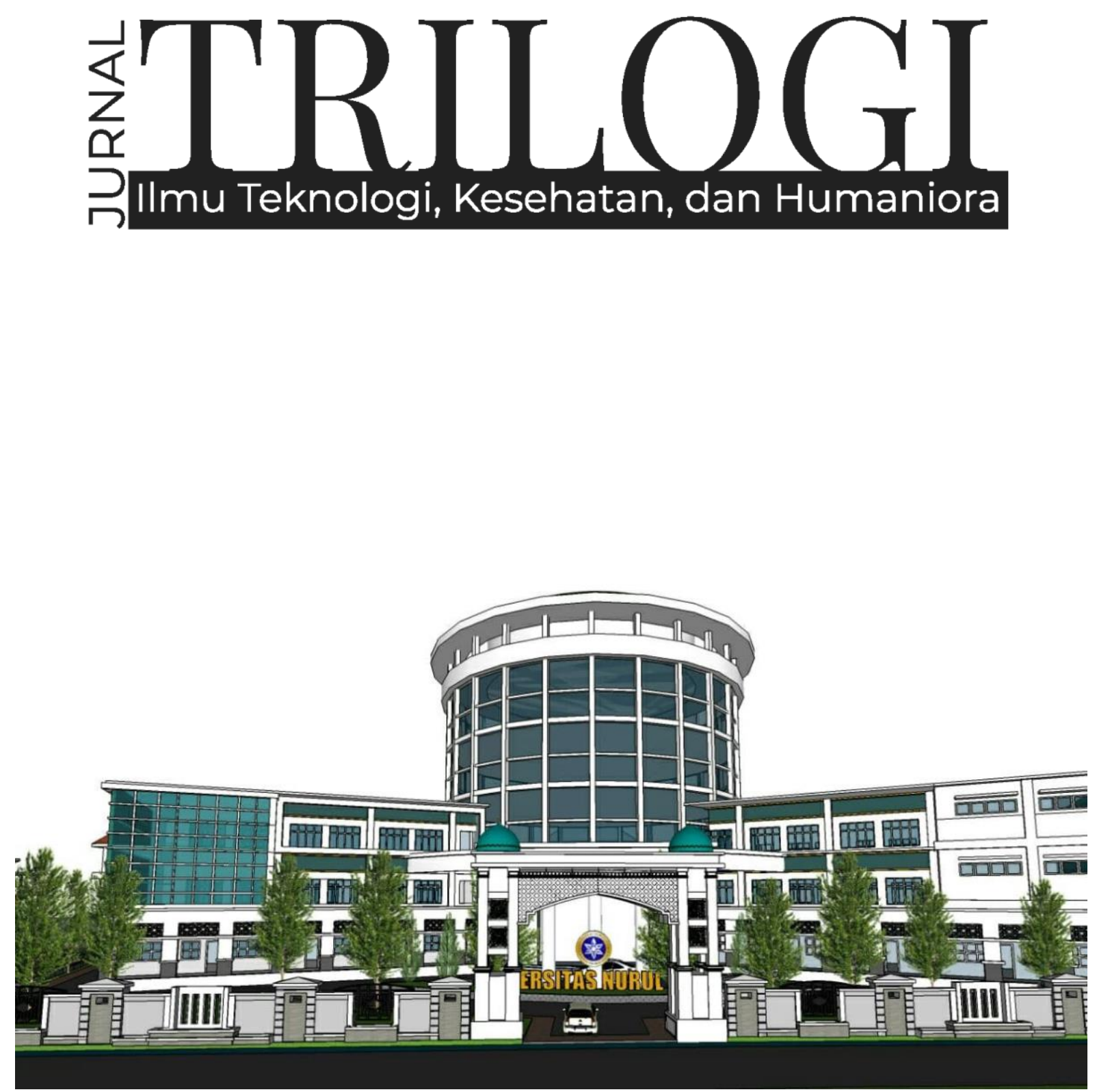

PENGEMBANGAN PENDIDIKAN DAN EKONOMI PESANTREN DI MASA PANDEMI COVID-19 


\section{犃BUOGI}

Vol. 2, No. 2, 2021

Editor in Chief

Achmad Fawaid, (SCOPUS ID: 57214837323)

\section{Managing Editors}

Hasan Baharun, (ID SCOPUS : 57200983602)

Sugiono Sugiono, (SCOPUS ID : 57199578160)

Ismail Marzuki, (SCOPUS ID: 57201500245

Subhan Rachman, (SCOPUS ID: 57192937912)

Nurul Huda, (SINTA ID: 6119615)

Syamsuri, (SINTA ID: 6116825)

Ridhatullah Assya'bani, (SINTA ID: 6200862)

\section{Peer Reviewers}

Miftahul Huda, (SINTA ID: 6171566), University of Antwerp, Belgium

Achmad Naufal Irsyadi, (SINTA ID: 6704870), Universitas Nurul Jadid, Indonesia

Gulpi Qorik Oktagalu P., (SINTA ID: 5982074) Universitas Nurul Jadid Probolinggo, Indonesia Hozairi, (SINTA ID: 166198), Universitas Islam Madura, Indonesia

Nur Hamid, (SINTA ID : 6744813), Univeristas Nurul Jadid Probolinggo, Indonesia Zainal Munir, (SINTA ID: 6672512), Universitas Nurul Jadid Probolinggo, Indonesia Sri Astutik Andayani, (SINTA ID: 6172559), Universitas Nurul Jadid Probolinggo, Indonesia Sukamto Sukamto, (SINTA ID: 5979034), Universitas Widya Gama Malang, Indonesia Deny Utomo, (SINTA ID: 6016108), Universitas Yudharta Pasuruan, Indonesia Fariz Alnizar, (SCOPUS ID: 6659824), UNUSIA Jakarta, Indonesia

Fuad Rahman, (SCOPUS ID: 57201474778), UIN Sulthan Thaha Saifuddin Jambi, Indonesia Saifuddin Zuhri Qudsy, (SCOPUS ID: 57213595165), UIN Sunan Kalijaga Yogyakarta, Indonesia Akhmad Anwar Dani, (SINTA ID: 14305), IAIN Surakarta, Indonesia

Maufur Maufur, (SINTA ID: 5989329), IAIN Kediri, Indonesia

Siti Mahmudah Noorhayati, (SINTA ID: 6726997), IAIN La Roiba Bogor, Indonesia Busro Busro, (SCOPUS ID: 57205022652), UIN Sunan Gunung Djati Bandung, Indonesia Akmal Mundiri, (SCOPUS ID: 57205059378), UNUJA Probolinggo, Indonesia

\section{Section Editor}

Ahmad Zubaidi, Universitas Nurul Jadid, Probolinggo, Indonesia 
TRILOGI: Jurnal IImu Teknologi, Kesehatan, dan Humaniora is a peer-reviewed journal, open-access journal which publishes original articles on various issues within technology, health, and social humanities, which include but are not limited to newrenewable energy, food-agriculture, health-pharmacy, transportation, informationcommunication technology, advanced-materials, maritime-infrastructre, social-artseducation, and religious studies based on academic and scientific research.

TRILOGI: Jurnal IImu Teknologi, Kesehatan, dan Humaniora seeks to publish a balanced mix of theoretical or empirical articles, case studies, review papers, comparative studies, exploratory papers, and book reviews. All accepted manuscripts will be possibly published both online and in printed forms.

Editorial Office:

TRILOGI: Jurnal IImu Teknologi, Kesehatan, dan Humaniora Lembaga Penerbitan, Penelitian, dan Pengabdian kepada Masyarakat (LP3M) Universitas Nurul Jadid, Paiton, Probolinggo, Jawa Timur, Indonesia 67291.

Phone: 088830 77077, Hp: 082318007953

Email: jurnal.trilogi@gmail.com

Website: https://ejournal.unuja.ac.id/index.php/trilogi/index 


\section{Tables of Content}

71-76

Pengaruh Metode Pembelajaran Daring dengan Aplikasi Google Classroom terhadap Hasil Belajar Siswa Madrasah Ibtidaiyah Nurul Mun'im Paiton Probolinggo

Feriska Listrianti, Lailatul Munawwaroh, Sayyidatul Arifa, Siti Aisyah

77-84

Inklusivitas dan Responsivitas Pesantren dalam Penanganan Pandemi Covid 19: Telaah Hidden Curriculum Pembelajaran di Pondok Pesantren Nurul Jadid

Zakiyah BZ, Uswatun Hasnah, Nafistur Rahmah

84-94

Integrasi Kurikulum Madrasah Diniyah dengan Lembaga Formal dalam Meningkatkan Mutu Lulusan di Sekolah Menengah Pertama (SMP) Nurul Jadid Paiton Probolinggo

Abdurrahman, Ika Fitri Anwar, Sofiya Mauliza, Nadya Afkarina

95-104

Some Issues on Time Deposit Financing: An Islamic Perspective on Mudharabah Agreement at Baitul Maal wa Tamwil (BMT) NU in Randuagung Lumajang

Saifuddin, Abdul Hafid, Hengki Wahyu Pratama

$105-110$

Analisis Pengembangan Potensi Ekonomi Keluarga melalui Unit Usaha Kapuk

Fahrudin, Iis Sa'diyah, Rizaldi Chandra Gunawan

111-117

Penguatan Ekonomi Pesantren melalui Pengembangan Ekonomi Masyarakat Pesisir: Pelajaran dari Pondok Pesantren Nurul Jadid Paiton Probolinggo

Achmad Febrianto, Muhammad Habibullah, Aksal Ilhamsyah

118-125

Prevensi Perilaku Konsumtif Persepektif Abraham Maslow dan Tri Logi Santri

Muhammad Syaiful Suib, Habibatur Rizkiyah, Fitria Nur Ain 
$126-136$

Manajemen Pengembangan Kurikulum Berorientasi pada Pembentukan Karakter

Moh Rifa'i, Fatimah Al Zahra, Abdurrahman Abdurrahman, Mukhlisin Saad

137-147

Home Industry, Kaderisasi, dan Santripreneur

Muh Hamzah, Aprilinda Dwi Kurniawati, Husnul Khotimah

148-157

Rancangan Pengelolaan Nirsampah Mandiri Skala Lembaga Pendidikan

Tirmidi, Eril Sinta Nuriyah, Rofi'ah

158-166

Parents' Knowledge and Commitment To Stimulate Child Development

Lailatul Fitriyah, Nurul Islamiyah, Auliya' Fatahillah

167-172

Implementasi Pembelajaran Akhlak Berbasis Multikultural pada Masa Pandemi di Madrasah Tsanawiyah Nurul Jadid Paiton Probolinggo

Abdullah, Yusrolana, Nur Laily

$173-183$

Implementasi Evaluasi Pembelajaran Daring (Online) melalui Home Visit

Moch Tohet, Moh. Bagus Abdillah, Adam Hakim Al Rizki

184-192

Efektivitas Pembelajaran Luring pada Mata Pelajaran Matematika selama Pandemi Covid-19

Zaenol Fajri, Sukron Junaidi, Hamdani Alfarisi 
P-ISSN: 2774-4574; E-ISSN: 2774-4582

TRILOGI, 2(2), Mei-Agustus 2021: (84-94) @2021 Lembaga Penerbitan, Penelitian, dan Pengabdian kepada Masyarakat (LP3M) Universitas Nurul Jadid Paiton Probolinggo

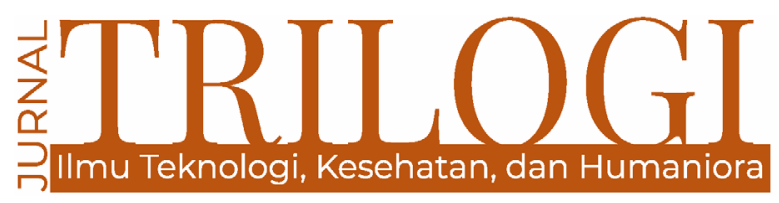

\title{
INTEGRASI KURIKULUM MADRASAH DINIYAH DENGAN LEMBAGA FORMAL DALAM MENINGKATKAN MUTU LULUSAN DI SEKOLAH MENENGAH PERTAMA (SMP) NURUL JADID PAITON PROBOLINGGO
}

\author{
Abdurrahman \\ Universitas Nurul Jadid, Probolinggo \\ rahman.gibol90@gmail.com \\ Ika Fitri Anwar \\ Universitas Nurul Jadid, Probolinggo \\ ikafitri2114@gmail.com
}

\author{
Sofiya Mauliza \\ Universitas Nurul Jadid, Probolinggo \\ maulizasofiya@gmail.com \\ Nadya Afkarina \\ Universitas Nurul Jadid, Probolinggo \\ afkarinanadya8@gmail.com
}

\begin{abstract}
This background of this research was the lack of student learning motivation in the Islamic boarding school to learn religious lesson that is actually the identity of the pesantren itself rather than common lessons. The position of Madrasah Diniyah as an educational institution that accommodates religious learning is increasingly marginalized by the presence of formal schools in Islamic boarding schools. The synergy between Madrasah Diniyah and formal institutions is often unbalanced so that many santri with religious knowledge are unmotivated. Departing from various concerns about religious learning, Islamic boarding schools took a firm stance by integrating the diniyah madrasah curriculum in formal institutions in anticipation of the motivation of santri to religious learning. The purpose of this study was to examine the integration curriculum of the Diniyah Madrasah Integration in a formal institution, explaining the Madrasah Diniyah integration curriculum model with formal institutions, and described the contribution of the diniyah madrasah to give birth to existential graduates to religious learning in formal institutions. This study also wants to affirm the role of madrasah diniyah as an identity of religious education in the Islamic boarding school environment. The research used a descriptive approach. The findings of this study are: First, Madrasah Diniyah was put together with a formal institution with a two-day division for Madrasah Diniyah and four days for formal institutions. Secondly, the Diniyah Madrasah Exam was first implemented before the formal examination. Third, the santri who did not pass the Madrasah Diniyah exam was not allowed to take a formal institution exam before removing. Fourth, improving the quality of graduates, santri first took control of Furudhul Ainiyah before taking the Madrasah Diniyah exam.
\end{abstract}

Keywords: integration curriculum; Madrasah diniyah; Formal institutions; Graduate Quality; Nurul Jadid 


\begin{abstract}
Abstrak
Penelitian ini dilatarbelakangi oleh fenomena merosotnya motivasi belajar santri di lingkungan pondok pesantren terhadap pelajaran agama yang sejatinya merupkan identitas dari pesantren itu sendiri dengan lebih mengedepankan pelajaran-pelajaran yang bersifat umum. Kedudukan Madrasah Diniyah sebagai lembaga pendidikan yang mengakomodir pembelajaran keagamaan semakin terpinggirkan dengan hadirnya sekolah-sekolah formal di pondok pesantren. Sinergi antara madrasah diniyah dengan lembaga formal sering kali tidak seimbang sehingga banyak santri dengan pengetahuan keagamaan yang masih jauh dari yang diharapkan. Berangkat dari berbagai kekhawatiran akan tergerusnya pelajaran agama di pondok pesantren, pondok pesantren mengambil sikap tegas dengan mengintegrasikan kurikulum madrasah diniyah pada lembagalembaga formal sebagai antisipasi akan memudarnya motivasi santri terhadap pembelajaran agama. Tujuan penelitian ini adalah untuk menelaah kurikulum integrasi madrasah diniyah pada lembaga formal, menjelaskan model kurikulum integrasi madrasah diniyah dengan lembaga formal, dan mendeskripsikan kontribusi madrasah diniyah untuk melahirkan lulusan yang eksistensial terhadap pembelajaran agama pada lembaga formal. Penelitian ini juga ingin menegaskan peran madrasah diniyah sebagai identitas pendidikan keagamaan di lingkungan pondok pesantren. Jenis penelitian yang dilakukan adalah kualitatif dengan pendekatan deskriptif. Adapun temuan dalam penelitian ini adalah: pertama, madrasah diniyah disatukan dengan lembaga formal dengan pembagian waktu dua hari untuk madrasah diniyah dan empat hari untuk lembaga formal. Kedua, ujian madrasah diniyah lebih dulu dilaksanakan sebelum ujian formal. Ketiga, santri yang tidak lulus ujian madrasah diniyah tidak diperkenankan mengikuti ujian lembaga formal sebelum melakukan remidi. Keempat, peningkatan mutu lulusan, santri terlebih dahulu menguasai Furudul Ainiyah sebelum mengikuti ujian madrasah diniyah.
\end{abstract}

Katakunci: Kurikulum Integrasi; Madrasah Diniyah; Lembaga Formal; Mutu Lulusan; Nurul Jadid

\section{Pendahuluan}

Dalam sejarahnya, madrasah diniyah banyak lahir dari lingkungan pondok pesantren sebagai wadah untuk memfasilitasi belajar santri sekaligus sebagai bentuk perlawanan terhadap lembagalembaga pendidikan model kolonial yang hanya berkutat pada pembelajaran sekuler (Nurhayati 2016). Bahkan dalam khazanah pesantren, kedudukan madrasah diniyah sangat penting sebagai lembaga yang mengakomodir seluruh mata pelajaran agama dengan jenjang kelas sebagaimana lembaga-lembaga formal. Kurikulum madrasah diniyah juga bersifat lebih akomodatif dan fleksibel daripada kurikulum pendidikan formal. Meski demikian, Iulusan madrasah diniyah diharapkan mempunyai kompetensi keislaman yang kaffah, baik yang bersifat ainiyah (personal) maupun kifayah (komunal), terutama di bidang ilmu Tauhid, Fiqih, Akhlak, dan Tasawuf. Pembahasan mengenai pendidikan pesantren juga seringkali mengundang diskusi panjang dan bahasan-bahasan yang tidak berkesudahan karena pesantren mempunyai daya tarik tersendiri yang mampu memikat masyarakat untuk dipelajari dan dikaji lebih dalam lagi secara berkelanjutan. Kekhasan dari pesantren sebagai lembaga keislaman yang di dalamnya meliputi sistem, metode, tata kelola, dan model adaptasi yang diimplementasikan terhadap pendidikan formal.

Madrasah diniyah di lingkungan pesantren terdiri dari berbagai jenjang, mulai dari tingkat Ibtidaiyah/Ulya, Tsanawiyah/Wustho, Aliyah/ Ulya hingga Ma'had Aly (Marzuki, Miftahuddin, and Murdiono 2020). Seiring berjalannya waktu, keberadaan madrasah diniyah terus mengalami peningkatan yang signifikan. Madrasah diniyah kemudian berkembang tidak hanya di lingkungan pondok pesantren saja. Beberapa kalangan di luar pesantren juga banyak yang mendirikan madrasah diniyah secara independen. Bedanya, jika di pesantren berjenjang hingga seusia anak-anak SMA (Ula, Wustha, dan Ulya), madrasah diniyah di luar pesantren hanya diperuntukkan bagi anakanak seusia sekolah dasar, setara tingkat ula di pesantren. Mata pelajarannya juga berbeda. Jika madrasah diniyah di lingkungan pesantren belajar gramatika bahasa Arab seperti Nahwu, Sharaf, Balaghah, Ilmu Hadis, Tafsir Quran, Fikih, Tauhid, hingga Tasawuf. Sedangkan di madrasah diniyah luar pesantren cukup mengajarkan BTQ (baca-tulis Quran), praktik sembahyang, dan praktik ibadah.

Terdapat tiga pilar utama pada madrasah diniyah. Pertama, filosofis, yaitu sebagai fondasi bahwa belajar di madrasah diniyah hukumnya adalah fardu ain (wajib personal) untuk 
dipertahankan sebagai lembaga yang "tafaqquh fiddin" melalui sumber belajar pada kitab-kitab salaf yang terdiri dari ide, cita-cita, dan sebagai simbol keagungan pesantren. Kedua, sosiologis, yaitu sebagai rujukan bahwa madrasah diniyah tidak berada pada ruang hampa (vacuum sepace), akan tetapi bagian dari sistem sosial yang luas dan dinamis, sehingga eksistensi madrasah diniyah tidak sekedar sebagai pelengkap, tetapi menjadi pilihan utama. Ketiga, yuridis, yaitu sebagai dasar mengembangkan kearifan bahwa di Indonesia berlaku sistem pendidikan nasional, sehingga jenis, dan bentuk perjenjangan satuan pendidikan yang namanya madrasah diniyah tersebut harus menyesuaikan dengan peraturan pendidikan yang ditetapkan dalam undang-undang (Saepudin 2018).

Secara yuridis, dasar pendidikan madrasah diniyah adalah UU No. 20 Tahun 2003, PP Nomor 19 tahun 2005, PP No. 55 Tahun 2007 tentang Pendidikan Agama dan Keagamaan, dikuatkan dengan Peraturan Menteri Agama Nomor 10 tahun 2010 tentang Organisasi dan Tata Kerja Kementrian Agama. Madrasah Diniyah sebagai lembaga pendidikan Islam legitimasinya telah diakui Pemerintah Indonesia. Legitimasi tersebut direalisasikan dalam Peraturan Pemerintah Republik Indonesia Nomor 55 Tahun 2007 Tentang Madrasah Diniyah Non-formal. Dalam pasal 21 disebutkan bahwa: 1) Pendidikan diniyah non-formal diselenggarakan dalam beberapa bentuk, di antaranya ialah pengajian Kitab Kuning, Majelis Taklim, Pendidikan Alquan, Diniyah Takmiliyah, atau sejenis; 2) Pendidikan diniyah non-formal sebagaimana dimaksud pada ayat 1 dapat berbentuk satuan pendidikan; 3) Pendidikan diniyah non-formal yang sudah berkembang untuk menjadi satuan pendidikan wajib memperoleh izin Departemen Agama Kabupaten/Kota setelah memenuhi ketentuan persyaratan pendirian satuan pendidikan (Wahid 2018).

Meski demikian, tantangan yang dihadapi madrasah diniyah semakin lama semakin kompleks. Tidak terkecuali di lingkungan pesantren itu sendiri. Salah satunya adalah motivasi belajar santri yang lebih mengutamakan pendidikan formal. Masa depan yang lebih jelas menjadi alasan utama mengapa pendidikan madrasah diniyah semakin kurang diminati. Masa depan dari lulusan pendidikan formal lebih menjanjikan seperti ijazah resmi untuk melamar pekerjaan, kelanjutan belajar ke sekolah-sekolah negeri maupun ke perguruan tinggi. Sementara madrasah diniyah tidak menyediakan ijazah resmi yang diakui pemerintah karena bersifat non-formal. Dari situ, minat belajar agama pun mulai mengalami kemunduran. Sistem pengajaran terbuka, perjenjangan, klasikal, berdirinya sekolah-sekolah formal, dan masuknya beberapa pelajaran yang bersifat saintifik merupakan perubahan yang cukup radikal yang terjadi di pondok pesantren. Pesantren pun memasuki babak baru dalam sejarah umat manusia, yaitu era modern.

Bahkan, tantangan tersebut semakin nampak ketika Menteri Pendidikan dan Kebudayaan hendak memberlakukan sekolah 5 hari dengan sistem full day school yang tertuang dalam Peraturan Menteri Pendidikan dan Kebudayaan Repubik Indonesia Nomor 23 Tahun 2017 Pasal 2 Ayat 1. Jelas, keadaan ini akan berdampak buruk pada madrasah diniyah yang biasanya masuk pada sore hari (Saepudin 2018). Padahal, keberadaan madrasah diniyah justru menjadi solusi dari minimnya pendidikan agama di lembaga-lembaga formal.

Keadaan yang sama juga pernah terjadi di Pondok Pesantren Nurul Jadid. Di mana semangat belajar santri di madrasah diniyah mulai mengalami penurunan. Kondisi seperti itu tentu akan berdampak kurang baik pada pendidikan agama santri yang pada dasarnya pesantren mengedepankan pendidikan agama. Pada prinsipnya, pesantren tidak bisa dilepasakan dari pendidikan agama. Sehingga pimpinan Pondok Pesantren Nurul Jadid dan segenap elemen yang ada di dalamnya berupaya keras untuk menjaga eksistensi madrasah diniyah-nya dengan berbagai kebijakan dan strategi di dalamnya. Keadaan seperti ini sangat menarik untuk dicermati lebih jauh lagi untuk melihat seberapa jauh upaya Pondok Pesantren Nurul Jadid untuk mewujudkan madrasah diniyah yang unggul dan melahirkan lulusan yang eksistensial terhadap pembelajaran agama.

Belakangan, eksistensi madrasah diniyah semakin lama kian mengkhawatirkan (Abdullah 2019). Dibutuhkan reformasi dalam pendidikan diharapkan mampu membenahi dan mengotimalisasikan sumber daya pendidikan agar menghasilkan orang-orang yang berilmu pengetahuan, terampil, dan bermoral (Tilaar 2017). Dalam upaya menjaga eksistensinya, dibutuhkan manajemen dan strategi yang tepat dan berkelanjuan. Manajemen pengembangan kurikulum pesantren merupakan suatu elemen yang mencakup perencanaan, pelaksanaan, 
dan penilaian kurikulum yang tentunya dilandasi nilai-nilai keislaman agar santri dapat mencapai tujuan pembelajaran secara efisien dan efektif (Abdurrahman 2018). Karena itu, faktor yang turut serta menentukan keberhasilan sebuah lembaga pendidikan, termasuk madrasah diniyah, salah satunya dengan adanya kurikulum yang jelas (Salahuddin 2012). Sehingga madrasah diniyah tidak hanya dipandang sebagai lembaga pelengkap di tengah menguatnya status lembaga formal.

\section{Metode}

Penelitian ini merupakan penelitian lapangan (field research) dengan pola studi kasus (Moleong 2017). Pendekatan penelitian yang digunakan dalam penelitian ini adalah pendekatan kualitatif dan jenis penelitian yang digunakan yaitu wawancara, pengamatan langsung dan studi dokumentasi. Selain itu, untuk mengukur tingkat kurikulum integrasi madrasah diniyah pada lembaga formal, menggunakan deskriptif yang berisi gambaran sejauh mana tingkat kurikulum integrasi madrasah diniyah pada lembaga formal dalam peningkatan mutu lulusan. Dengan adanya pemilihan metode ini diharapkan bisa memberikan gambaran tentang integrasi kurikulum madrasah diniyah pada lembaga formal di SMP Nurul Jadid.

Untuk memperoleh data tersebut, dipergunakan teknik pengumpulan data melalui observasi lapangan, wawancara mendalam dan studi dokumentasi. Observasi dilakukan untuk mengamati secara langsung proses KBM madrasah diniyah yang dilaksanakan di SMP Nurul Jadid. Wawancara dilakukan terhadap sejumlah informan kunci seperti Kepala Sekolah, Koordinator Madrasah Diniyah, Wakil Kepala Bagian Kurikulum SMP Nurul Jadid, dan Wakil Koordinator Madrasah Diniyah. Studi dokumentasi dilakukan untuk menggali data penunjang yang diperoleh dari dokumen-dokumen untuk selanjutnya dideskripsikan.

\section{Hasil dan Pembahasan}

Berdasarkan hasil wawancara, pengamatan, dan kajian dokumentasi di SMP Nurul Jadid, dapat dijelaskan sebagai berikut:

\section{a. Sejarah Singkat Pondok Pesantren Nurul Jadid}

Pondok Pesantren Nurul Jadid didirikan oleh KH. Zaini Mun'im pada tahun 1950 Masehi yang bertempat di Desa Karanganyar, Kecamatan
Paiton, Kabupaten Probolinggo, Jawa Timur. Saat ini, Pondok Pesantren Nurul Jadid menempati areal seluas $14 \mathrm{Ha}$. Secara Geografis letak Pondok Pesantren Nurul Jadid berada pada : 73' BT. Berjarak $33 \mathrm{KM}$ arah timur Kota Probolinggo atau $133^{\circ} 40^{\prime}$ LS, 113 KM arah timur Surabaya. Pondok Pesantren Nurul Jadid pada pertama kalinya (1950-1976) dipimpin dan diasuh langsung oleh $\mathrm{KH}$. Zaini Mun'im dengan dibantu oleh beberapa pengurus senior. Kepemimpinan Pondok Pesantren diteruskan secara berturut-turut oleh $\mathrm{KH}$. Moh. Hasyim Zaini (1976-1984), Drs. KH. Abd. Wahid Zaini, SH. (1984-2000), dan sekarang adalah KH. Moh. Zuhri Zaini, BA. (2000-sekarang).

Saat ini, Pondok Pesantren Nurul Jadid telah mempunyai sejumlah gedung sekolah dan madrasah. Sekolah terdiri dari lembaga pendidikan klasikal yang mempunyai afiliasi ke Diknas dan Depag. Selain itu, Pondok Pesantren Nurul Jadid juga mempunyai lembaga diniyah dengan kurikulum yang mandiri. Disebut mandiri karena penyusunan kurikulumnya menjadi hak penuh dari pengelola Pesantren. Lembaga pendidikan di Pondok Pesantren Nurul Jadid berafiliasi pada dua jalur kementrian, yaitu Depag yang di antaranya adalah Taman Kanak-Kanak (TK) dan Raudlatul Atfal (RA), Madrasah Ibtidaiyah (MI), Madrasah Tsanawiyah (MTs), dan Madrasah Aliyah (MA). Sedangkan yang berafiliasi pada Diknas antara lain adalah Sekolah Menengah Pertama (SMP), Sekolah Menengah Kejuruan (SMK), dan Sekolah Menengah Atas (SMA).

Berdirinya Pondok Pesantren Nurul Jadid memang bukan sekedar untuk pemenuhan kebutuhan keilmuan, melainkan juga penjagaan budaya, penyebaran etika dan moralitas keagamaan. Tak heran, pada periode awal ini santri lebih diarahkan agar supaya lebih memahami bentuk aplikasi dari teori ilmuilmu keagamaan yang mereka pelajari dalam kitab-kitab kuning (klasik). Sehingga nantinya, para santri dapat mengamalkan teori ilmu-ilmu keagamaan secara tepat dan benar ketika sudah terjun di tengah-tengah masyarakat. Bentuk aplikasi ilmu keagamaan tersebut dilakukan dalam bentuk pendampingan kepada masyarakat (Mursyid 2016).

\section{b. Madrasah Diniyah Nurul Jadid}

Madrasah Diniyah Nurul Jadid merupakan salah satu lembaga yang berada di bawah naungan Yayasan Pondok Pesantren Nurul Jadid yang diberi kepercayaan untuk memberdayakan kemampuan santri dalam membangun dan memahami nilai- 
nilai keagamaan. Berdirinya Madrasah Diniyah Nurul Jadid dilatarbelakangi oleh kenyataan bahwa masih banyak santri di pengujung tahun 90-an mulai mengalami pergeseran dalam menekuni ilmu agama, terutama di bidang kajian kitabkitab kuning sebagai elemen penting dan ciri khas pesantren.

Pada awal berdirinya, Madrasah Diniyah Nurul Jadid belum mempunyai sarana dan prasarana yang cukum memadai. Belum ada asrama, kantor, gedung madrasah, dan sarana belajar lainnya. Gagasan didirikannya madrasah diniyah di Pondok Pesantren Nurul Jadid bermula pada tahun 80an yang masih terdiri dari kelompok-kelompok kecil bahtsul masail yang tersebar di berbagai asrama santri. Kelompok-kelompok kecil tersebut terus berlangsung meski dengan perkembangan yang masih pasang surut hingga tahun 1997. Perkembangan Madrasah Diniyah Nurul Jadid mulai mengalami kemajuan ketika almarhum $\mathrm{KH}$. Romzi mengelola madrasah tersebut dengan sistem sentralisasi. Secara bertahap, kelompok tersebut akhirnya berubah menjadi badan otonom di bawah Yayasan Nurul Jadid.

Semula madrasah diniyah di Pondok Pesantren Nurul Jadid dilaksanakan pada malam hari antara jam 20.00 hingga 22.00 WIB mengikuti lembaga formalnya dengan kegiatan lima hari belajar karena liburnya dua malam, yaitu malam Jumat dan malam Selasa. Seluruh siswa SMP Nurul Jadid yang berstatus santri wajib mengikuti kegiatan madrasah diniyah yang juga dilaksanakan di SMP Nurul Jadid pada malam harinya. Meski kegiatan di malam hari ini telah berjalan lama, akan tetapi pelaksanaannya masih kurang efektif karena energi santri sudah terkuras sejak pagi, terutama di lembaga-lembaga formal yang kegiatan belajarnya antara jam 07.30 hingga jam 13.00 WIB. Sekalipun ada jeda antara jam 13.00 hingga jam 15.00 WIB, namun masih terdapat kegiatan tambahan di antara jam jeda tersebut, seperti Bimbingan Membaca Kitab Kuning (BMK), kursus bahasa asing (Inggris-Arab), desain grafis, maupun kegiatan life skill lainnya (Bakir, 2021). Sorenya selepas sembahyang Ashar, santri wajib mengikuti pengajian kitab kuning secara umum di Masjid Jami' yang diampuh langsung oleh pengasuh Pondok Pesantren Nurul Jadid.

Praktis, madrasah diniyah yang dilaksanakan pada malam hari tersebut kurang berjalan maksimal. Sekalipun kurikulum madrasah diniyah disusun seoptimal mungkin, melakukan perombakan kepengurusan, terus mengadakan pembenahan serta evaluasi setiap bulan, akan tetapi masih banyak santri yang mengikuti kegiatan belajar ala kadarnya. Sumbu dari persoalan rendahnya motivasi belajar santri tersebut tentu bukan terletak pada kurikulumnya, mata pelajaran maupun tenaga pendidik yang tersedia. Akan tetapi pada timing yang kurang sesuai dengan energi dan konsentrasi santri. Di mana dalam hampir sehari penuh mereka telah mengikuti kegiatan belajar wajib dan ekstrakurikuler di lembaga formal. Padatnya kegiatan tersebut membuat konsentrasi dan motovasi mereka kedodoran (Bakir, 2021). Dibutuhkan waktu yang cukup dan tepat sesuai dengan kondisi santri. Sehingga keberlangsungan madrasah diniyah terus berjalan dengan baik. Bagaimana pun madrasah diniyah tidak lain adalah ruh dari pendidikan pesantren.

Pada tahun pelajaran 2017-2018, pimpinan dan pengurus Pondok Pesantren Nurul Jadid yang berada di bawah binaan Biro Pendidikan mengubah waktu kegiatan madrasah diniyah ke pagi hari antara jam 07.30 hingga 08.50 dengan pembagian jam belajar masing-masing 40 menit per mata pelajaran. Sedangkan kegiatan belajar (formal) SMP Nurul Jadid berlangsung antara jam 09.00 hingga 14.30. Lembaga-lembaga formal di bawah Yayasan Pondok Pesantren Nurul Jadid dilibatkan untuk memfasilitasi ruang kelasnya untuk ditempati siswa-siswi Madrasah Diniyah. Inilah yang kemudian menjadi cikal-bakal adanya kurikulum integrasi antara lembaga formal dengan madrasah diniyah. Kegiatan belajar madrasah diniyah yang mendahului jam pelajaran lembaga formal diharapkan mampu mendongkrak motivasi belajar santri di madrasah diniyah. Waktu belajar pun dibuat seefisien mungkin dengan mengurangi jam pelajaran madrasah diniyah dari per mata pelajaran 45 menit menjadi 40 menit. Jeda dari madrasah diniyah ke SMP juga berlangsung sangat singkat, hanya 10 menit (Bakir, 2021). Strategi ini dibuat supaya santri tidak berlama-lama di kelas diniyah dan konsentrasi belajarnya masih tetap terjaga untuk menyambung dengan pembelajaran di lembaga formal.

Meski demikian, kegiatan belajar madrasah diniyah yang dilangsungkan di pagi hari tersebut ternyata juga belum maksimal. Berbagai kendala masih muncul di lapangan. Di antaranya adalah; (1) kelas siswa madrasah diniyah tidak sama dengan kelas di SMP-nya karena kemampuan keagamaan siswa yang berbeda-beda. Sehingga dalam satu kelas madrasah diniyah terdiri dari kelas VII,VIII, dan IX SMP. Keadaan ini tidak kondusif dan membuat siswa harus pindah- 
pindah kelas dari kelas diniyah ke kelas SMP; (2) tenaga pendidik juga kualahan karena harus silang mengajar dengan lembaga lain sekalipun sama-sama di bawah naungan Yayasan Pondok Pesantren Nurul Jadid seperti guru madrasah diniyah yang kebetulan juga mempunyai jam mengajar di SMA Nurul Jadid, guru SMP Nurul Jadid diminta mengajar di madrasah diniyah yang berada di SMK Nurul Jadid, begitu seterusnya; (3) kurangnya tenaga pengajar yang benar-benar murni sebagai guru diniyah dan murni sebagai guru SMP Nurul Jadid. Sehingga tugas mengajar pun tumpang tindih. Tidak banyak perubahan mendasar dari sistem baru tersebut (Ghafur, 2021). Sederet fakta tersebut dapat digarisbawahi bahwa untuk mengembangkan madrasah diniyah yang benar-benar berjalan dengan baik bukanlah pekerjaan mudah.

Eksperimen yang baru berjalan satu tahun tersebut kemudian dihentikan. Kegiatan madrasah diniyah kembali dirombak total dan mencari jalan keluar dari sederet persoalan yang dihadapi madrasah diniyah. Pimpinan dan pengurus Pondok Pesantren Nurul Jadid kembali mengkaji ulang pelaksanaan madrasah diniyah di pagi hari tersebut (Ghafur, 2021).

\section{c. SMP Nurul Jadid}

Berdirinya SMP Nurul Jadid tidak bisa dilepaskan dari kerangka berpikir KH. Zaini Mun'im yang jauh ke depan. Ini bermula dari rasa prihatin beliau yang tinggi terhadap generasi umat Islam. Ceritanya, ketika akan mengunjungi salah satu putranya yang belajar di Pondok Pesantren Darul Ulum, Jombang. Ketika sampai di kota, beliau sangat prihatin terhadap pelajar umum (SMP/SMA) dengan pakaian olahraga serta pergaulan putra dan putri yang sudah mengabaikan nilai-nilai akhlakul karimah dan budaya keindonesiaan. Dari peristiwa itulah, beliau berpikir dan berdiskusi panjang dengan pengurus Pesantren untuk meyelamatkan putraputri umat Islam dengan mendirikan pendidikan umum (formal) di Pesantren, tentu pada waktu itu pesantren-pesantren masih terasa sangat asing menerima kehadiran pendidikan umum (formal) yang ditengarai oleh sebagian umat Islam sebagai "warisan" kolonial Belanda (M. Ishaq 2018). Akan tetapi $\mathrm{KH}$. Zaini Mun'im mengambil keputusan tegas untuk bertekad mendirikan lembaga umum, karena beliau juga berpikir bahwa nantinya lembaga umum akan sangat dibutuhkan oleh umat Islam. Dari hasil beberapa pertimbangan mendasar dalam menyiapkan kader santri yang multifungsi, maka pada tahun 1970 didirikanlah SMP Nurul Jadid. Pada awal berdirinya terdapat 29 siswa baru yang mendaftar dan menempati ruang yang sangat sederhana. Kepala Sekolah pertama dipercayakan kepada santri senior, Bapak Suari Abdur Rozak, BA. sejak tahun 1970 hingga 1973. Pada tahun 1973 terjadi pergantian kepala sekolah. Pimpinan SMP Nurul Jadid dilimpahkan kepada Bapak Mursyid Mahfud, BA. Pada masa ini (1973-1975) berdasarkan penetapan Kanwil Dikbud Propinsi Jawa Timur Kabin PMUP No 706/ KP/73. SMP Nurul Jadid dinyatakan telah masuk dalam lingkungan binaan SMP Negeri Kraksaan, termasuk dalam pelaksanaan Ujian Nasional (Raharjo, 2021).

Sekarang ini, SMP Nurul Jadid telah mempunyai banyak wadah pengembangan bakat dan kreativitas peserta didik yang terkemas dalam sejumlah organisasi, di antaranya adalah (Ghafur, 2021):

\section{Organisasi Siswa Intra Sekolah (OSIS)}

Sebagaimana kebanyakan sekolah formal setingkat SLTP dan SLTA, SMP Nurul Jadid juga mempunyai Organisasi Siswa Intra Sekolah yang bertujuan untuk menunjang kegiatan sekolah dan mengembangkan jiwa organisator siswa SMP Nurul Jadid.

2. Language Intensive Program of SMP Nurul Jadid (LIPS)

Language Intensive Program of SMP Nurul Jadid adalah program pengembangan bahasa asing (Inggris-Arab) di bawah naungan SMP Nurul Jadid. Program ini dilakukan dengan pembinaan secara khusus dan diasramakan sehingga peserta didik dapat berkomunikasi aktif berbahasa asing dalam sehari-hari. Program ini mempunyai wadah organisasi siswa yang bernama International Language Organization (ILO).

3. Media Pers Siswa (Majalah Iqro)

Iqro' adalah sebuah nama organisasi siswa SMP Nurul Jadid yang secara khusus mendalami media pers dan jurnalistik yang dalam perkembangannya kemudian dijadikan nama sebuah majalah yang terbit setiap satu tahun sekali. Majalah tersebut menjadi sebuah aplikasi dari materi pers dan jurnalistik yang telah diajarkan. Di dalam majalah tersebut terdapat beberapa macam rubrik termasuk yang berbahasa Inggris dan berbahasa Arab.

4. Palang Merah Remaja (PMR)

Dalam kebanyakan sekolah formal, Palang Merah Remaja (PMR) dijadikan media untuk melatih tanggung jawab dan rasa sosial anak 
terhadap alam sekitarnya terutama kepada sesama. SMP Nurul Jadid akan mewujudkan apa yang menjadi tujuan utama dari organisasi ini. Dari PMR, SMP Nurul Jadid memfasilitasi pesera didiknya untuk tetap berkembang dalam bidang sosial dengan mengadakan kegiatan semacam ini. 5. Majelis Permusyawarahan Kelas (MPK)

Majelis Permusyawarahan Kelas (MPK) adalah organisasi yang diadakan untuk mengawasi kinerja Organisasi Intra Sekolah (OSIS) selama masa jabatan kepemimpinannya.

6. Seni Hadrah Al-Wahidiyah

Seni Hadrah Al-Wahidiyah adalah kesenian yang mewadahi kekreatifan peserta didik untuk mengembangkan bakatnya dalam bidang seni suara dan alat-alat musik tradisional.

\section{d. Kurikulum Integrasi}

Upaya Pondok Pesantren Nurul Jadid untuk menyelenggarakan Madrasah Diniyah yang unggul dan terus survive sebagai identitas pesantren pada puncaknya melahirkan beberapa keputusan penting hingga sekarang. Setelah melakukan serangkaian evaluasi dan koordinasi antarpimpinan lembaga, akhirnya ditemukan solusi yang dipandang cukup efektif dan efisien, yaitu mengintegrasikan kurikulum madrasah diniyah pada lembaga formal dengan pembagian waktu yang teratur. Satu terobosan penting yang kemudian paten hingga hari ini adalah; (1) madrasah diniyah disatukan (integrasi) dengan lembaga formal dengan pembagian jam yang sama; (2) membagi enam hari dalam dua kegiatan belajar, empat hari untuk lembaga formal dan dua hari untuk madrasah diniyah; (3) masingmasing hari ditambah satu jam pelajaran yang semula 7 jam menjadi 8 jam; (4) tidak boleh ada guru yang mengajar di dua lembaga, formal dan madrasah diniyah, harus memilih salah satunya. Sehingga murni sebagai guru formal atau murni sebagai guru madrasah diniyah (Raharjo, 2021). Di SMP Nurul Jadid, kegiatan madrasah diniyah dilaksanakan pada hari Rabu dan Kamis dengan masing-masing 8 jam pelajaran perhari.

Dalam kurikulum intergrasi madrasah diniyah pada lembaga formal, beberapa mata pelajaran mengalami penyederhananaan maupun penambahan yang signifikan. Di antaranya adalah mata pelajaran Pendidikan Jasmani dan Kesehatan (PENJASKES) dan Seni Budaya ditiadakan untuk diganti pada mata pelajaran Ilmu Nahwu dan Ilmu Sharaf. Sedangkan mata pelajaran Pendidikan Agama Islam diambil alih oleh madrasah diniyah untuk dikembangkan lebih
Iuas lagi pada mata pelajaran keislaman yang lebih komplit seperti Tauhid, Fikih, Hadis, Aswaja, dan Sejarah Islam (Tarikh). Kurikulum integrasi ini kemudian menjadi satu inovasi yang cukup efektif dalam upaya peningkatan Iulusan SMP Nurul Jadid (Raharjo, 2021). Dengan adanya integrasi tersebut, maka pembelajaran mata pelajaran yang mempunyai keterkaitan dengan Pendidikan Agama Islam ditiadakan dan digabung menjadi satu waktu di Madrasah Diniyah. Praktis, dengan perubahan format mata pelajaran, mata pelajaran di madrasah diniyah mengalami penambahan.

Langkah yang ditempuh Pondok Pesantren Nurul Jadid untuk mengintegrasikan Madrasah Diniyah ke dalam lembaga formal meliputi tiga elemen penting, yaitu: (1) memadatkan seluruh kegiatan pembelajaran; (2) memadukan bahan ajar; (3) memadukan metode pembelajaran. Langkah ini merupakan suatu terobosan yang cukup berani, bahkan mungkin belum ada di pondok pesantren yang lain. Dengan demikian, terobosan tersebut bisa ditumbuhkembangkan untuk menghasilkan lulusan yang religius sekaligus responsif terhadap perkembangan zaman. Besar harapan, dengan kurikulum integrasi ini, santri mampu menerapkannya dalam kehidupan sehari-hari sebagai ukuran minimal yang harus dipenuhi oleh setiap santri ketika pulang ke masyarakat. Karena bagaimanapun, kurikulum merupakan pondasi dari pelaksanaan pendidikan sekaligus berfungsi sebagai alat ukur utama perkembangan pembelajaran yang terjadi di setiap lembaga (Raharjo, 2021).

Selain itu, diintegrasikannya kurikulum madrasah diniyah ke lembaga formal adalah upaya untuk mengubah stigma bahwa selama ini (dalam kurun waktu yang sudah lama) terdapat dikotomi antara tenaga pendidik di lembaga formal dengan lembaga pendidik di lembaga non formal seperti madrasah diniyah (Bakir, 2021). Dengan penyamarataan seperti ini, setiap tenaga pendidik dari latar belakang satuan pendidikan yang berbeda, baik formal maupun non formal bisa bekerjasama dan tidak merasa canggung karena sudah tidak ada lagi dikotomi antara lembaga non formal dengan lembaga formal, juga tidak ada dikotomi tenaga pendidik madrasah diniyah dengan tenaga pendidik lembaga formal, semua adalah tenaga pendidik di bawah binaan Yayasan Pondok Pesantren Nurul Jadid.

\section{e. Mutu Lulusan}

Dalam lingkungan pendidikan, lebih-lebih di lingkungan pondok pesantren, kepuasan yang 
diharapkan masyarakat akan terwujud manakala pesantren berhasil membuktikan mutunya yang berkelanjutan dan lulusan dari pesantren dapat berguna terhadap masyarakat (Siswanto 2016). Sebagai sebuah institusi yang memproduk manusia pintar dalam beragama, pastinya pesantren harus bisa menghasilkan (output) santri yang dan berguna bagi masyarakat luas. Output tersebut selain beraplikasi secara individual, tetapi juga berdampak positif secara sosial. Artinya, sosok santri tidak hanya pada posisi personal santri itu sendiri, namun juga mempunyai imbas pada komunitas di mana santri tersebut berada.

Sementara mutu pendidikan merupakan suatu proses dalam melakukan sebaik-baiknya sejak dari awal mula lembaga didirikan dan terus melakukan perbaikan secara berkesinambungan dan berkala, mulai dari penetapan visi, misi, tujuan, sasaran, pelaksanaan, pengendalian, pemantauan, dan pengevaluasian yang dalam hal ini ditujukan pada substansi dari pendidikan yang lebih berarti, mulai dari input, proses, output, hingga di tingkat outcome (Mutohar 2013). Dalam hal ini, Madrasah Diniyah Nurul Jadid dituntut untuk memberikan pembinaan atau praktik keislaman serta menyiapkan lulusan yang mampu menjadikan nilai-nilai agama Islam sebagai tolok ukur keberhasilan santri dalam belajar di pesantren.

Dalam pengembangan kurikulum madrasah diniyah pastinya disesuaikan dengan kepentingan madrasah diniyah itu sendiri, disesuaikan dengan landasan filosofis pesantrennya, umpamanya untuk menyiapkan generasi muslim yang mampu memahami agamanya, membaca Al-Qur'an dengan baik dan berbudi luhur. Untuk itu prinsip relevansi menjadi penting, supaya dapat menyesuaikan bahan ajar yang diprogramkan dengan landasan tersebut dan lingkungan serta kebutuhan hidup para santri. Di samping itu perlu pula menyesuaikan dengan perkembangan ilmu pengetahuan dan teknologi, terutama dalam bidang teknologi pendidikan. Madrasah Diniyah sering tertinggal dalam bidang ini, karena itu komunikasi dengan perubahan-perubahan yang terjadi tidak boleh terhenti dan putus begitu saja (Bakir, 2021). Adapun implikasi yang dapat dilihat dari intensitas yang memberi keuntungan besar dapat diproduksi pesantren terhadap masyarakat luas, di antaranya adalah keuntungan yang sifatnya pragmatis terhadap aspek yang berdimensi budaya, pendidikan, dan sosial. Paradigma ini dapat diselaraskan dengan teori human capital.

Upaya SMP Nurul Jadid untuk melahirkan lulusan yang religius dan berkarakter islami memberlakukan satu standar lulusan yang kemudian dikenal Furudlul Ainiyah. Sekalipun sebagai program tambahan, program Furudlul Ainiyah menjadi program yang sangat strategis karena mempunyai standar khusus. Program ini dibentuk guna membekali peserta didik dengan kemampuan baca-tulis Al-Qur'an, hukum Islam (Fikih), akidah, dan ketaatan dalam ibadah. Kegiatan ini dilakukan setiap pekan di hari Kamis, dengan kurikulum terpadu dengan Pondok Pesantren Nurul Jadid dengan melibatkan guruguru madrasah diniyah.

Selain itu, untuk mendukung pembinaan peserta didik, SMP Nurul Jadid terus meningkatkan mutu lulusannya di mana setiap santri yang akan mengikuti ujian semester di SMP Nurul Jadid harus menguasai Furudlul Ainiyah. Santri tidak diperkenankan mengikuti ujian semester di sekolah formalnya jika Furudlul Ainiyah-nya belum tuntas. Begitu juga ketika hendak mengikuti Ujian Nasional, santri harus memperoleh sertifikat lulus dari SMP Nurul Jadid sebagai tanda lulus Furudlul Ainiyah-nya. Pembina dari kegiatan Furudlul Ainiyah dibina langsung oleh guru mapelnya. Sebagaimana dikatakan pembina Madrasah Diniyah di SMP Nurul Jadid, kegiatan Furudlul Ainiyah terangkum dalam tabel berikut:

\begin{tabular}{|c|c|c|c|c|}
\hline \multirow{2}{*}{ Materi Furudul Ainiyah } & \multicolumn{2}{|c|}{ Penilaian } & \multirow{2}{*}{ Tanggal } & \multirow{2}{*}{ Paraf } \\
\hline & Tuntas & Belum Tuntas & & \\
\hline 1. Akidah & & & & \\
\hline $\begin{array}{l}\text { a. Peserta didik dapat menyebutkan tiga pilar utama } \\
\text { akidah (Iman, Islam, Ihsan) }\end{array}$ & & & & \\
\hline $\begin{array}{l}\text { b. Peserta didik dapat menjelaskan pengertian dari pilar } \\
\text { utama akidah }\end{array}$ & & & & \\
\hline c. Peserta didik dapat menghafal rukun Islam & & & & \\
\hline d. Peserta didik dapat menghafal rukun iman & & & & \\
\hline $\begin{array}{l}\text { e. Peserta didik dapat menghafal aqoidul khamsin (50 } \\
\text { sifat Allah) }\end{array}$ & & & & \\
\hline
\end{tabular}


f. Peserta didik dapat menyebutkan pengertian iman kepada malaikat dan tugas para malaikat

g. Peserta didik dapat menyebutkan pengertian iman kepada kitab suci dan para nabi yang membawanya

h. Peserta didik dapat menyebutkan 25 Rasul yang wajib diketahui

\section{Fikih}

a. Peserta didik dapat menjelaskan tentang pengertian thaharah

b. Peserta didik dapat menyebutkan tujuh macam air suci dan menyucikan

c. Peserta didik dapat menjelaskan pengertian tayamum

d. Peserta didik dapat menjelaskan syarat debu yang bisa digunakan bersuci

e. Peserta didik dapat menyebutkan alat-alat yang bisa dipakai untuk istinjak

f. Peserta didik dapat menjelaskan alat-alat yang biasa digunakan menyamak

g. Peserta didik dapat menjelaskan pengertian najis

h. Peserta didik dapat menyebutkan macam-macam najis

i. Peserta didik dapat menjelaskan cara bersuci dari najis dan hadas

j. Peserta didik dapat mempraktikkan cara berwudlu'

k. Peserta didik dapat mempraktikkan cara bertayamum

I. Peserta didik dapat mempraktikkan cara bersuci dari hadas besar

m. Peserta didik dapat mempraktikkan cara menghilangkan najis

n. Peserta didik dapat memahami macam-macam darah wanita

o. Peserta didik dapat menjelaskan ketentuan sembahyang bagi wanita yang haid dan nifas

p. Peserta didik dapat menyebutkan syarat dan rukun shalat

q. Peserta didik dapat memahami waktu shalat fardlu

r. Peserta didik dapat menghafal bacaan-bacaan dalam shalat

s. Peserta didik dapat menjelaskan hal-hal yang membatalkan shalat

t. Peserta didik dapat menyebutkan syarat imam shalat

u. Peserta didik dapat menyebutkan syarat wajib shalat Jumat

\section{Tajwid (Al-Qur'an)}

a. Peserta didik dapat menjelaskan pengertian ilmu tajwid

b. Peserta didik dapat memahami 5 hukum mim mati dan tanwin (idhar, ikhfa', idgham bi ghunnah, idgham bila ghunnah, dan iklab)

c. Peserta didik dapat memahami bacaan mad dan jenis-jenisnya

d. Peserta didik dapat menjelaskan idgham mitslain, idgham mutajanisain, dan idgham mutaqaribain

e. Peserta didik dapat menjelaskan pengertian laam takrif ("al" syamsiyah dan "al" qamariyah) 
f. Peserta didik dapat memahami bacaan dan tingkatan qalqalah

g. Peserta didik dapat menjelaskan pengertian ikhfa' bi ma'nal jadid

h. Peserta didik dapat menjelaskan hukum bacaan $R a$ (tafkhim dan tarkik)

i. Peserta didik dapat menjelaskan pengertian waqaf dan ibtida

j. Peserta didik dapat memahami ayat-ayat sajdah (sujud tilawah)

\begin{tabular}{ll}
\hline 4. & Doa Harian \\
\hline a. & Peserta didik dapat menghafal doa setelah berwudlu \\
\hline b. & Peserta didik dapat menghafal doa adzan \\
\hline c. & $\begin{array}{l}\text { Peserta didik dapat menghafal doa makan dan } \\
\text { minum }\end{array}$ \\
\hline d. & Peserta didik dapat menghafal doa setelah selesai \\
& membaca Al-Qur'an \\
\hline e. & Peserta didik dapat menghafal doa masuk WC \\
\hline f. & Peserta didik dapat menghafal doa keluar dari WC \\
\hline g. & Peserta didik dapat menghafal doa masuk masjid \\
\hline h. & Peserta didik dapat menghafal doa keluar dari \\
& masjid \\
\hline i. & Peserta didik dapat menghafal doa masuk rumah \\
\hline j. & Peserta didik dapat menghafal doa keluar rumah \\
\hline
\end{tabular}

Penguatan kurikulum integrasi madrasah diniyah pada lembaga formal melalui Furudlul Ainiyah meliputi beberapa materi agama, di antaranya Tauhid/Akidah, Fikih, Al-Qur'an, dan doa-doa harian sehingga santri tidak hanya mumpuni dalam bidang sains dan teknologi, akan tetapi juga mumpuni dalam praktik keagamaan sehari-hari. Dengan adanya program Furudlul Ainiyah tersebut, diharapkan menjadi bekal santri untuk mengamalkan dasar-dasar ilmu keislaman dalam kehidupan sehari-hari. Selain itu, Furudlul Ainiyah menjadi wadah dalam menjaga tradisi keilmuan salaf (klasik) sebagai identitas pesantren.

\section{KESIMPULAN}

Madrasah diniyah sebagai lembaga yang mengakomodir materi-materi keagamaan di berbagai tempat dituntut untuk terus melakukan perubahan sekaligus dengan inovasi berkelanjutan dalam upaya merawat dan mempertahankan eksistensinya. Madrasah Diniyah yang berada di Pondok Pesantren Nurul Jadid juga tidak luput dari arus perubahan yang terus menuntut untuk melakukan serangkaian inovasi dan penyesuaian agar tetap survive sebagai lembaga keislaman. Upaya strategis yang dilakukan adalah dengan mengintegrasikan kurikulum madrasah diniyah pada lembaga-lembaga formal di dalamnya, termasuk di SMP Nurul Jadid. Selain itu, upaya meningkatkan mutu lulusan yang dapat mengamalkan dasar-dasar ajaran agama Islam seperti tauhid, fikih, akhlak, dan baca-tulis Al-Qur'an juga terus ditekankan. Madrasah diniyah yang diselenggarakan di SMP Nurul Jadid mempunyai program unggulan dalam membina peserta didik yang dikenal dengan istilah Furudlul Ainiyah. Program Furudlul Ainiyah juga menjadi prasyarat santri untuk mengikuti ujian semester di lembaga formal. Sehingga madrasah diniyah di SMP Nurul Jadid dengan program tambahan berupa Furudlul Ainiyah mampu mendongkrak motivasi santri untuk belajar agama lebih mendalam. Efektivitas kurikulum integrasi ini tampak pada keaktifan belajar peserta didik yang sebelumnya hanya berjalan apa adanya.

\section{Daftar Pustaka}

Abdullah, Mukhammad. 2019. "School Culture to Serve Performance of Madrasah in Indonesia." Qudus International Journal of Islamic Studies. https://doi.org/10.21043/ qijis.v7i1.4572.

Abdurrahman, Abdurrahman. 2018. "Implementasi Manajemen Kurikulum Pesantren Berbasis Pendidikan Karakter." AT-TURAS: Jurnal Studi Keislaman. https://doi.org/10.33650/ at-turas.v4i2.336. 
M. Ishaq. 2018. "KH. ABDUL WAHID ZAINI DAN PENGEMBANGAN PONDOK PESANTREN NURUL JADID PAITON PROBOLINGGO." UIN Sunan Ampel Surabaya.

Marzuki, Miftahuddin, and Mukhamad Murdiono. 2020. "Multicultural Education in Salaf Pesantren and Prevention of Religious Radicalism in Indonesia." Cakrawala Pendidikan. https://doi.org/10.21831/ cp.v39i1.22900.

Moleong, Lexy J. 2017. "Metodologi Penelitian Kualitatif (Edisi Revisi)." In PT. Remaja Rosda Karya.

Mursyid, Mursyid. 2016. "Pilihan Rasional Kiai Dan Desain Pendidikan Toleransi Di Pondok Pesantren Tebuireng Dan Nurul Jadid." ISLAMICA: Jurnal Studi Keislaman. https:// doi.org/10.15642/islamica.2016.11.1.27-55.

Mutohar, Prim Masrokan. 2013. Manajement Mutu Sekolah: Strategi Peningkatan Mutu Dan Daya Saing Lembaga Pendidikan Islam. Ar Ruzz Media.

Nurhayati, Eti. 2016. "A MODEL OF EDUCATION FOR WOMEN (A Case Study in Madrasah Muallimat PUI Majalengka - West Java)." Jurnal Cakrawala Pendidikan. https://doi. org/10.21831/cp.v1i1.8360.
Saepudin, Juju. 2018. "INTEGRASI PEMBELAJARAN MADRASAH DINIYAH TAKMILIYAH KE SEKOLAH." Jurnal SMaRT (Studi Masyarakat Dan Tradisi).

Salahuddin, Marwan. 2012. "PENGEMBANGAN KURIKULUM MADRASAH DINIYAH TAKMILIYAH." Cendekia: Jurnal Kependidikan Dan Kemasyarakatan. https://doi. org/10.21154/cendekia.v10i1.401.

Siswanto, Siswanto. 2016. "DESAIN MUTU PENDIDIKAN PESANTREN." KARSA: Jurnal Sosial Dan Budaya Keislaman. https://doi. org/10.19105/karsa.v23i2.726.

Tilaar, H.A.R. 2017. "Pendidikan Untuk Mengembangkan Identitas Bangsa." Abad: Jurnal Sejarah.

Wahid, Abdul. 2018. "INTEGRASI PENDIDIKAN KARAKTER DALAM PEMBELAJARAN DI MADRASAH DINIYAH." Tarbawi: Jurnal Pendidikan Islam. https://doi.org/10.34001/ tarbawi.v15i1.715. 